\title{
Enrofloxacin Transformation on Shewanella oneidensis MR-1 Reduced Goethite during Anaerobic-Aerobic Transition
}

\author{
Wei Yan, Jianfeng Zhang, ${ }^{\ddagger}$ and Chuanyong Jing* ${ }^{* \dagger}$ \\ ${ }^{\dagger}$ State Key Laboratory of Environmental Chemistry and Ecotoxicology, Research Center for Eco-Environmental Sciences, Chinese \\ Academy of Sciences, P.O. Box 2871, Beijing 100085, China \\ ${ }^{\ddagger}$ School of Environmental and Municipal Engineering, Xi'an University of Architecture and Technology, Xi'an 710055, China
}

Supporting Information

\begin{abstract}
Antibiotics pollution has become a critical environmental issue worldwide due to its high ecological risk. In this study, rapid degradation of enrofloxacin (ENR) was observed on goethite in the presence of Shewanella oneidensis MR-1 during the transition from anaerobic to aerobic conditions. The abiotic reactions also demonstrated that over $70 \%$ with initial concentration of $10 \mathrm{mg} \mathrm{L}^{-1}$ ENR was aerobically removed within 5 min by goethite with adsorbed $\mathrm{Fe}$ (II), without especial irradiation and strong oxidants. The results of spin trap electron spin resonance (ESR) experiments provide evidence that $\mathrm{Fe}(\mathrm{II}) / \mathrm{Fe}$ (III) complexes facilitate the generation of $\bullet \mathrm{OH}$. The electrophilic attack by $\bullet \mathrm{OH}$ opens the quinolone ring of ENR and initiates further transformation reactions. Five transformation products were identified using high performance liquid chromatography-quadrupole time-of-flight mass spectrometry and the ENR degradation process was proposed accordingly. The identification of ENR transformation products also revealed that both the surface adsorption and the electron density distribution in the molecule determined the reactive site and transformation pathway. This study highlights an important, but often underappreciated, natural process for in situ degradation of antibiotics. With the easy migration of the goethite-MR-1 complex to the anaerobic/aerobic interface, the environmental fates of ENR and other antibiotics need to be seriously reconsidered.
\end{abstract}

\section{INTRODUCTION}

The overuse of antibiotics poses a serious risk to human and ecological health worldwide. ${ }^{1,2}$ Enrofloxacin (ENR), a representative fluoroquinolone antibiotic, has been extensively used in veterinary pharmaceuticals. The continuously increasing use of antibiotics in the past decades has led to their partitioning to minerals such as goethite ${ }^{3,4}$ and a proliferation of bacteria in the environment containing highly resistant genes for ENR and other antibiotics. ${ }^{5}$

Microorganisms drive the biogeochemical cycles of pollutants in the environment. A well-studied example is the respiration of dissimilatory iron-reducing bacteria (DIRB) that can promote the reductive dissolution of ferric (oxyhydr)oxides in reducing conditions and generate $\mathrm{Fe}(\mathrm{II}){ }^{6}$. The biogenic $\mathrm{Fe}$ (II) on ferric (oxyhydr)oxide surfaces is so active that it can significantly enhance the reduction rate of a wide range of organic and inorganic pollutants, such as nitroaromatics, ${ }^{7-9}$ insecticides, ${ }^{10}$ antibiotics, ${ }^{11}$ and toxic metals. ${ }^{12,13}$

Compared with the studies carried out under anaerobic conditions, the impact of biogenic $\mathrm{Fe}$ (II) adsorbed on ferric (oxyhydr)oxide surfaces is less understood regarding the fate of pollutants during the transition from anaerobic to aerobic conditions. In fact, the assembly of colloids and bacteria originally under anaerobic conditions can easily migrate to and encounter the anaerobic-aerobic interfaces, such as in flooded paddy soils, ${ }^{14}$ plant roots in waterlogged soil, ${ }^{15}$ and sand-water interface. ${ }^{16}$ In such a scenario, the adsorbed Fe(II) would be readily oxidized once in contact with oxygen, since oxygen is a more thermodynamically favorable terminal electron acceptor $\left(\mathrm{E}_{\mathrm{H}}{ }^{\circ}(\mathrm{W})=+0.81 \mathrm{~V}\right.$ for $\left.\mathrm{O}_{2(\mathrm{~g})} / \mathrm{H}_{2} \mathrm{O}\right)$, relative to $\mathrm{Fe}(\mathrm{III})$ minerals $\left(-0.05 \mathrm{~V}\right.$ for $\left.\mathrm{FeOOH}_{(\mathrm{s})} / \mathrm{FeCO}_{3(\mathrm{~s})}\right) .{ }^{11}$ It has been reported in recent studies that several synthetic mixed-valence iron oxides, such as $\mathrm{Fe} @ \mathrm{Fe}_{2} \mathrm{O}_{3}$ nanowires, could activate the dissolved molecular oxygen by electron transfer to generate reactive oxygen species (ROS), which can be used for the oxidative degradation of organic contaminants. ${ }^{17,18}$ Considering the ubiquitous distribution of iron oxides and DIRB, we hypothesize that the surface process involving DIRB-mediated $\mathrm{Fe}(\mathrm{III})$ reduction followed by aerobic $\mathrm{Fe}(\mathrm{II})$ oxidation is an important natural pathway for the biotransformation of antibiotics.

The objective of this study was to explore the ENR transformation mediated by $\mathrm{Fe}$ (III)-reducing bacteria and goethite during the transition from anaerobic to aerobic conditions. The surface interaction mechanisms and ENR transformation pathways were investigaged by using spin trap electron spin resonance (ESR) spectroscopy and quadrupole

Received: June 18, 2016

Revised: September 12, 2016

Accepted: September 16, 2016

Published: September 16, 2016 

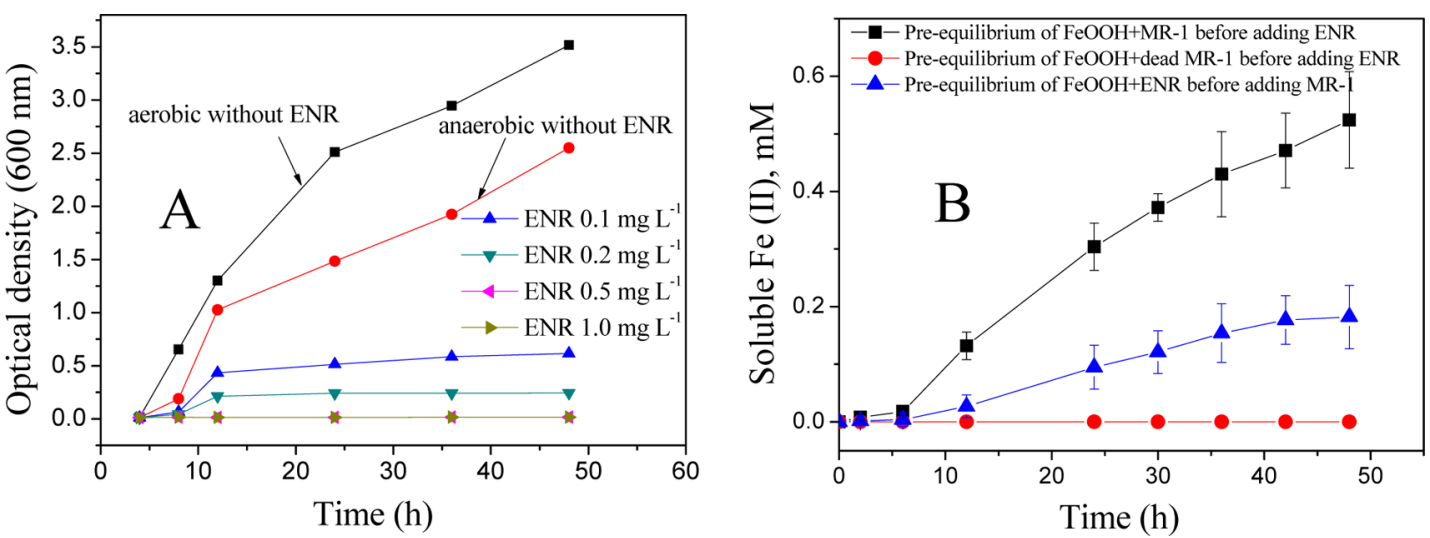

Figure 1. (A) Growth curves of MR-1 under aerobic (black squares) and anaerobic (red circles) conditions in the absence of ENR, and in the presence of $0.1-1 \mathrm{mg} \mathrm{L}^{-1}$ ENR under aerobic condition. (B) Fe(III) reduction by MR-1 under different treatments with $2 \mathrm{mg} \mathrm{L} \mathrm{L}^{-1}$ ENR. The time "0" means the moment of ENR (black squares A, and red circles in B) or MR-1(blue triangle in B) addition.

time-of-flight mass spectrometry (Q-TOF-MS). The mechanistic insights gained from this study can further our understanding on the underappreciated microbial-mediated interfacial reactions under redox transition and help us to reevaluate the environmental fates of ENR and related antibiotics.

\section{EXPERIMENTAL SECTION}

Materials. Enrofloxacin (ENR, 98\%), 5,5-dimethyl-1pyrolin- $N$-oxide (DMPO, ACS reagent grade), DMSO and five structural analogues of ENR, namely, 8-hydroxyquinoline (HQN, 99\%), flumequine (FLU, 98\%), 1-(2-fluorophenyl)piperazine (FPP, 98\%), nicotinic acid (NA, 99.5\%), quinoline (QN, 98\%), were used as received from Sigma-Aldrich (St. Louis. MO). Stocks of target compounds were prepared in Nanopure water (18.2 $\Omega$ from Milli-Q water system) at $100 \mathrm{mg}$ $\mathrm{L}^{-1}$. All stocks were protected from light, stored at $4{ }^{\circ} \mathrm{C}$, and used within a week of preparation.

Goethite and Shewanella oneidensis MR-1 were selected as a typical $\mathrm{Fe}(\mathrm{III})$ oxyhydroxide and DIRB species, respectively, based on their ubiquitous distribution in the environment and high importance toward ecological systems. Goethite was synthesized via the hydrolysis of iron nitrate as shown in our previous report. ${ }^{19}$ The BET surface area $\left(84.7 \mathrm{~m}^{2} \mathrm{~g}^{-1}\right)$ was determined with ASAP2000 (Micromeritics Instrument Corp.). The point of zero charge (PZC) of goethite was determined to be 8.9 with a Zetasizer Nano ZS (Malvern Instruments, U.K.). The microbial incubation of MR-1 were conducted following our reported study. ${ }^{19}$ The details are provided in the Supporting Information (SI). The minimal inhibitory concentration (MIC) test for ENR is also detailed in the SI.

Biotic Reactions with ENR. The biotic reaction experiment was carried out in sterile serum bottles in a glovebox $\left(100 \% \mathrm{~N}_{2}\right)$ with a $\mathrm{O}_{2}$ level lower than $1 \mathrm{ppm}$. All solutions were prepared using deoxygenated DI water, which were boiled and purged with $\mathrm{N}_{2}$ (99.99\%) for at least $1 \mathrm{~h}$, and transferred into the glovebox for overnight pre-equilibration before use. After being capped with butyl rubber stoppers and aluminum crimp seals, the bottles were transferred out of the glovebox and shaken at $30{ }^{\circ} \mathrm{C}$ on an oscillator at $100 \mathrm{rpm}$. Four batch experiments were conducted: (1) a control containing preequilibrated goethite $\left(1 \mathrm{~g} \mathrm{~L}^{-1}\right)$ and $\operatorname{ENR}\left(2 \mathrm{mg} \mathrm{L}^{-1}\right)$; (2) preequilibration of goethite with dead MR-1 (pasteurized treatment at $85{ }^{\circ} \mathrm{C}$ for $1 \mathrm{~h}$ ) for 1 day before adding ENR;
(3) pre-equilibration of goethite with active MR-1 $\left(10^{6} \mathrm{CFU}\right.$ $\mathrm{mL}^{-1}$ ) for 1 day before adding ENR; (4) pre-equilibration of goethite with ENR for 1 day before adding MR-1. Each treatment was incubated for $120 \mathrm{~h}$ under anaerobic conditions followed by air exposure for $48 \mathrm{~h}$. One $\mathrm{mL}$ aliquots were periodically withdrawn and passed through a $0.22 \mu \mathrm{m}$ filter for HPLC measurements. Triplicate batch experiments were performed in darkness at $30{ }^{\circ} \mathrm{C}$. For comparison, abiotic experiments containing ENR, goethite and $\mathrm{Fe}$ (II) were also conducted and the detailed process is provided in the SI.

Spin Trap Electron Spin Resonance (ESR) spectroscopy. The ESR experiments were conducted in ambient air condition with a Bruker (Billerica, MA) ER 200 D-SRC spectrometer operating at $9.8 \mathrm{GHz}$ and a cavity equipped with a Bruker Aquax liquid sample cell. The basic system in this study consisted of $1 \mathrm{~g} \mathrm{~L}^{-1} \alpha$-FeOOH suspension, $\mathrm{Fe}(\mathrm{II})$ with various concentrations, and DMPO $(100 \mathrm{mM})$ as spin-trapping agent for $\bullet \mathrm{OH}$ and superoxide $\left(\mathrm{O}_{2}^{-}\right)$in PIPES buffer $(\mathrm{pH} \mathrm{6.8,} 10$ $\mathrm{mM})$. To further determine the species of reactive radicals involved, $\bullet \mathrm{OH}$ scavenger DMSO was used. The solutions were recorded $1 \mathrm{~min}$ after the $\mathrm{Fe}(\mathrm{II})$ addition. The acquisition parameters for the experiments were according to the report of Huang et al. as follows: ${ }^{20}$ scan range, $100 \mathrm{G}$; field set, $3405 \mathrm{G}$; time constant, $200 \mathrm{~ms}$; scan time, $100 \mathrm{~s}$; modulation amplitude, $0.25 \mathrm{G}$; modulation frequency, $100 \mathrm{kHz}$; receiver gain, $1.25 \times$ $10^{5}$; and microwave power, $20 \mathrm{~mW}$. The hyperfine splitting constants were measured by using the simulation software WinSim version 0.96 (NIEHS).

Analytical Procedures. The details of sample analysis, including HPLC-FL, HPLC-ESI-Q-TOF-MS, colorimetric assay of $\mathrm{Fe}(\mathrm{II})$ are provided in the SI.

\section{RESULTS AND DISCUSSION}

Protection of MR-1 from ENR Attack by Goethite Adhesion. Since ENR is a broad spectrum antibiotic, its specific toxic effect on strain MR-1 was first investigated by analyzing its minimal inhibitory concentration (MIC) with or without goethite. The results show that MR-1 cells can hardly survive in the presence of $0.5 \mathrm{mg} \mathrm{L}^{-1}$ ENR or higher (Figure 1A). Conversely, once preadsorbed on goethite, MR-1 can resist up to $2 \mathrm{mg} \mathrm{L}^{-1}$ ENR as evidenced by the continual increase in $\mathrm{Fe}$ (II) which was biogenerated by MR-1 (black squares in Figure 1B). To confirm that this $\mathrm{Fe}(\mathrm{II})$ increase was induced by MR-1, a control incubation experiment was 

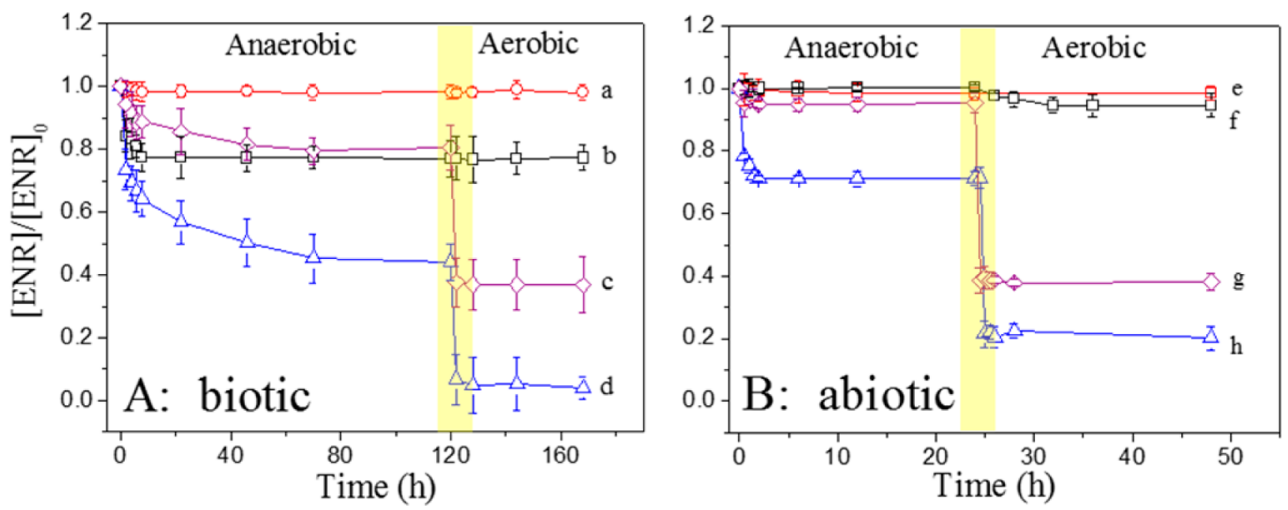

Figure 2. Change in ENR concentration as a function of time in MR-1 incubated goethite (A, biotic system) and in goethite with $0.8 \mathrm{mM}$ Fe(II) (B, abiotic system) under anaerobic and aerobic conditions. a, e: controls containing pre-equilibrated ENR and goethite; b: pre-equilibration of goethite with dead MR-1 cells for 1 day before adding ENR; c: pre-equilibration of goethite with ENR for 1 day before adding MR-1; d: pre-equilibration of goethite with MR-1 for 1 day before adding ENR; f: ENR with Fe(II); g: pre-equilibration of goethite with ENR for 1 day before adding Fe(II); h: pre-equilibration of goethite with $\mathrm{Fe}(\mathrm{II})$ for 1 day before adding ENR. The time "0" means the moment of ENR (b, d, h), MR-1 (c), or Fe(II) (g) addition.

performed by pre-equilibrating dead MR-1 cells with goethite before ENR addition, and no Fe(II) was detected (red circles in Figure 1B). When goethite was pre-equilibrated with ENR before adding MR-1 (blue triangles in Figure 1B), the reduction of $\mathrm{Fe}$ (III) to $\mathrm{Fe}$ (II) was appreciably suppressed. This suppression is not primarily due to the physical-chemical inhibition by the adsorbed ENR molecules, since the occupied surface area by ENR relative to the whole surface area of goethite is negligible ( $R=0.44 \%$, calculation detailed in the SI). Thus, these observations imply that adsorption on goethite protected MR-1 from the ENR attack.

Biotic Reaction of ENR with Goethite and MR-1 Cells. The change in ENR concentration as a function of incubation time exhibited a drastic difference between MR-1 and control samples, especially during the transition from anaerobic to aerobic conditions (yellow region in Figure 2A). In the absence of MR-1 (lines a and e), the ENR concentration did not change once adsorption reached equilibrium, even in the transition from an anaerobic to aerobic environment. In the presence of dead MR-1 cells, negligible ENR change was observed under both anaerobic and aerobic conditions (line b). For the scenarios containing active MR-1 cells (lines $\mathrm{c}$ and d), the ENR concentration decreased slowly under the anaerobic condition, followed by a substantial drop during the transit from anaerobic to aerobic conditions, and then remained unchanged thereafter. Specifically, when MR-1 was added prior to ENR in the anaerobic condition, a higher rate $\left(0.108 \mathrm{~h}^{-1}\right.$ vs $\left.0.024 \mathrm{~h}^{-1}\right)$ and extent ( 0.48 vs 0.32$)$ in ENR decrease were observed (line c vs $\mathrm{d}$ in Figure $2 \mathrm{~A}$, the reaction rates were calculated at the initial time, $(t=0 \mathrm{~h})$ and the reaction extents were calculated by the differences occurring at each transition moment $(t=120 \mathrm{~h})$ ). This ENR decrease facilitated by MR-1 was in agreement with the yield of $\mathrm{Fe}$ (II) (Figure 1B). Reductive dissolution of goethite induced by MR-1 could generate fresh surfaces. ${ }^{21,22}$ These in situ generated surface sites contributed to the slow ENR decrease under anaerobic conditions. No transformation of ENR occurred under anaerobic conditions since no degradation product of ENR was detected.

Abiotic Reaction of ENR with Goethite in the Presence of $\mathrm{Fe}$ (II). To determine the role of biogenic $\mathrm{Fe}(\mathrm{II})$ in ENR removal, we simplified the MR-1 mediated reaction using an abiotic system containing ENR, goethite, and $\mathrm{Fe}(\mathrm{II})$
(Figure 2B and Figure S2). The effects of goethite, Fe(II), and $\mathrm{O}_{2}$, on the ENR dissipation were first investigated (Figure S3). An increased ENR dissipation was observed with the increase in goethite content (Figure S3A). Different from goethite, no positive correlation was found between $\mathrm{Fe}(\mathrm{II})$ concentration and ENR dissipation (Figure S3A). Fe(II) from 0 to $2 \mathrm{mM}$ enhanced the ENR dissipation, but inhibited the ENR removal when $\mathrm{Fe}(\mathrm{II})$ was higher than $2 \mathrm{mM}$, indicating that the ENR dissipation was regulated by the adsorbed $\mathrm{Fe}(\mathrm{II})$. Besides, as shown in Figure S3B, the ENR removal rate after $4 \mathrm{~h}$ remained the same for $\mathrm{O}_{2}$-bubbling system (red curve) and nonbubbling system (blue curve). This result indicates that $\mathrm{O}_{2}$ only expedite the reaction rate, but had no influence on the extent of ENR removal, though $\mathrm{O}_{2}$ is an important prerequisite.

For a given abiotic system for ENR reaction, no significant loss in soluble ENR was found in the control containing $\mathrm{Fe}$ (II) and ENR ( $p>0.05$, line $\mathrm{f}$ in Figure 2B, and lines a,e in Figure $\mathrm{S} 2$ ), verifying that precipitation of $\mathrm{Fe}$ (II) has negligible effect on ENR adsorption. Meanwhile, ENR adsorption on goethite was stable and no desorption occurred during the experiment (lines b, f in Figure S2).

A prominent discrepancy was found in the pre-equilibration of goethite and ENR followed by Fe(II) addition (Figure S2A), where $>70 \%$ ENR was removed within 5 min under aerobic conditions in contrast to $<10 \%$ ENR removal under anaerobic conditions. These results clearly suggest that $\mathrm{Fe}(\mathrm{II})$, biogenic or abiotic, is reactive on goethite in the presence of $\mathrm{O}_{2}$, resulting in substantial ENR removal. Considering its rapid kinetics and great extent in ENR dissipation compared with the controls (Figure S2A), we propose that ROS may be generated and involved in the ENR removal.

ESR Studies. To further validate the radical degradation mechanism and possible radical species formed during the reaction process, ESR experiments were carried out by using DMPO as the spinning-trapping regent for hydroxyl radical and superoxide radical anion.

As shown in Figure 3, no obvious signal of spin adduct was observed in samples containing only $\mathrm{Fe}$ (II) or goethite (Figure $3 a, b)$. The weak signal in Figure $3 a$ was due to the reaction of $\mathrm{Fe}(\mathrm{II})$ with DMPO (Figure S4). The 1:2:2:1 ESR signal with hyperfine splitting parameters of $\mathrm{a}^{\mathrm{H}}=\mathrm{a}^{\mathrm{N}}=14.9 \mathrm{G}$ appeared in the spectra of goethite with $\mathrm{Fe}$ (II) and MR-1 mediated 


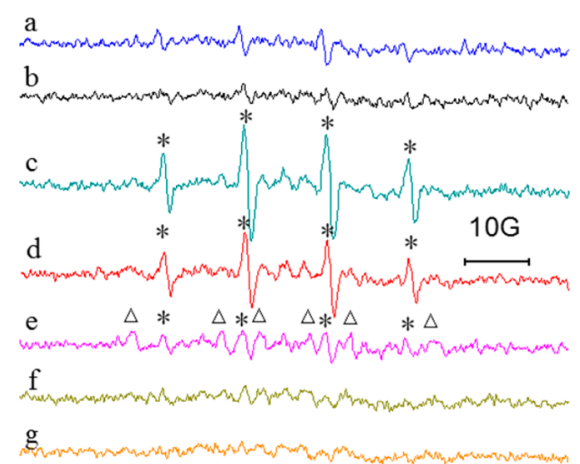

$* \mathrm{DMPO} / \mathrm{HO} \cdot \triangle \mathrm{DMPO} / \mathrm{CH}_{3}$

Figure 3. ESR spectra of DMPO hydroxide radical adducts produced by goethite and $\mathrm{Fe}(\mathrm{II})$ in the presence of DMPO. a: $\mathrm{Fe}(\mathrm{II})$ solution; b: goethite suspension; c: goethite with $\mathrm{Fe}(\mathrm{II})$; d: bioreduced goethite suspension by MR-1; e: goethite with $\mathrm{Fe}(\mathrm{II})$ in the presence of DMSO; f: bioreduced goethite by MR-1 in the presence of DMSO; g: goethite which adsorbed ENR $(10 \mathrm{mg} / \mathrm{L})$ in advance with $\mathrm{Fe}(\mathrm{II})$. Reactions were carried out at room temperature in PIPS buffer $(\mathrm{pH}$ 7.0, $0.1 \mathrm{M})$. All reaction mixtures contained $100 \mathrm{mM}$ DMPO. Concentrations for the components are $\mathrm{Fe}(\mathrm{II}), 0.01 \mathrm{mM}$; goethite, $1 \mathrm{~g} /$ L; MR-1, $10^{6} \mathrm{CFU} \mathrm{mL}{ }^{-1}$; DMPO, $100 \mathrm{mM}$; DMSO, 5\%, V:V. ESR spectra were recorded $1 \mathrm{~min}$ after the interactions at room temperature under normal room-lighting conditions. The hyperfine splitting constants for DMPO/HO• were $\mathrm{a}^{\mathrm{H}}=\mathrm{a}^{\mathrm{N}}=14.9 \mathrm{G}$ and for $\mathrm{DMPO} / \bullet \mathrm{CH}_{3}$ were $\mathrm{a}^{\mathrm{H}}=23.3 \mathrm{G} \mathrm{a}{ }^{\mathrm{N}}=16.3 \mathrm{G}$.

goethite, which is characteristic for spin adduct $\mathrm{DMPO} / \bullet \mathrm{OH}$ (Figure $3 \mathrm{c}, \mathrm{d}){ }^{23}$ After the addition of the $\bullet \mathrm{OH}$ scavenger (DMSO), the DMPO/•OH signal was appreciably suppressed. Instead, minor DMPO adduct with a methyl radical (DMPO/ $\left.-\mathrm{CH}_{3}\right){ }^{24}$ characterized by an intensity ratio of $1: 1: 1: 1: 1: 1$ and hyperfine splitting parameters of $\mathrm{a}^{\mathrm{H}}=23.3 \mathrm{G}, \mathrm{a}^{\mathrm{N}}=16.3 \mathrm{G}$, was instead observed (Figure 3e,f). These ESR results provide direct evidence for $\bullet \mathrm{OH}$ radical existence in $\mathrm{Fe}(\mathrm{II})$-goethite couple. When pre-equilibration of goethite with ENR was carried out before adding $\mathrm{Fe}(\mathrm{II})$ (Figure $3 \mathrm{~g}$ ), no $\mathrm{DMPO} / \bullet \mathrm{OH}$ signal was observed, suggesting that ENR adsorbed on the surface may instantaneously consume $\bullet \mathrm{OH}$ prior to the formation of $\mathrm{DMPO} / \bullet \mathrm{OH}$.

Adsorbed $\mathrm{Fe}$ (II) on iron hydroxides can lower the standard reduction potential of the $\mathrm{Fe}(\mathrm{II}) / \mathrm{Fe}$ (III) redox couple, enabling $\mathrm{Fe}(\mathrm{II})$ a strong reductant under anaerobic conditions. $^{10,11}$ Similarly, during the transition from anaerobic to aerobic conditions in this study, as shown in the TOC Art, the $\mathrm{Fe}(\mathrm{II}) / \mathrm{Fe}$ (III) intervalence charge transfer facilitates the reduction of adsorbed oxygen at the solid/liquid interface, ${ }^{17}$ leading to the generation of ROS, including $\bullet \mathrm{OH}^{17,18,25}$ Although the dissolved $\mathrm{Fe}$ (II) alone has negligible contribution to $\bullet \mathrm{OH}$ radical generation (Figure $3 \mathrm{a}$ ), it plays an important and multiple role in the ENR degradation when ROS has been generated at $\mathrm{Fe}(\mathrm{II}) /$ goethite surfaces. On one side, dissolved $\mathrm{Fe}(\mathrm{II})$ can react with the generated $\bullet \mathrm{O}_{2}^{-}\left(\mathrm{Fe}(\mathrm{II})+\mathrm{HO}_{2}\right.$ / $\bullet \mathrm{O}_{2}{ }^{-} \rightarrow \mathrm{Fe}(\mathrm{III})+\mathrm{H}_{2} \mathrm{O}_{2}$ ), which can accelerate the generation of $\bullet \mathrm{OH}$ radical. ${ }^{26} \mathrm{On}$ the other side, the excess dissolved $\mathrm{Fe}(\mathrm{II})$ may compete with ENR to react with $\bullet \mathrm{OH}$ radical $\left(\mathrm{Fe}(\mathrm{II})_{(\mathrm{aq})}+\right.$ $\left.\bullet \mathrm{OH}+\mathrm{H}^{+} \rightarrow \mathrm{Fe}(\mathrm{III})_{s}+\mathrm{H}_{2} \mathrm{O}\right)$, which inhibited the ENR dissipation (Figure S3A).

It is noteworthy that the microbial mediated generation of $\bullet \mathrm{OH}$ in this study is a Fenton-like process with unique characteristic. ${ }^{27}$ The generation of ROS by classical Fenton-like reactions has a limited applicable $\mathrm{pH}$ range, usually $2.5-3.5{ }^{28}$
On the contrary, the highest ENR degradation on bioreduced goethite was obtained at neutral $\mathrm{pH}$ (Figure S5). This observation can be explained by the fact that the acidic condition inhibits the adsorption of bioreduced $\mathrm{Fe}$ (II) on goethite due to charge repulsion, ${ }^{29}$ whereas the alkaline condition promotes the oxidation of bioreduced $\mathrm{Fe}$ (II) by dissolved $\mathrm{O}_{2} \cdot{ }^{30}$ Thus, only a neutral $\mathrm{pH}$ facilitates the formation of the $\mathrm{Fe}(\mathrm{II}) / \mathrm{Fe}(\mathrm{III})$ complex, and this neutral $\mathrm{pH}$ adaptation endows the microbial mediated redox process a crucial one in natural environments.

Reaction Pathways. To determine the reaction pathways, the degradation ratio of ENR was first exploited, along with its five structural analogues, which were FLU, HQN, QN, FPP, and NA (Figure 4). The high degradation ratio of ENR and

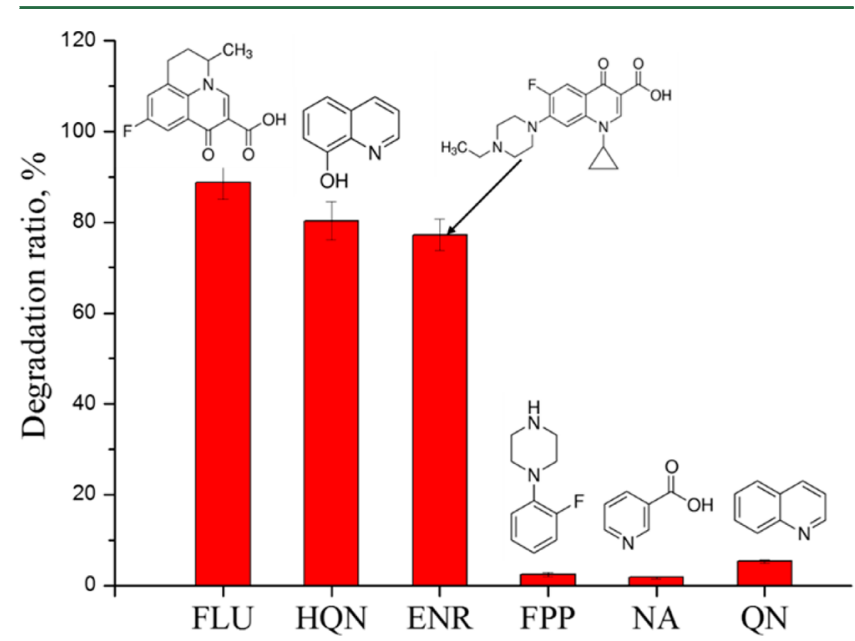

Figure 4. Comparison of degradation rate of ESR and its structural analogues in suspension of goethite with adsorbed $\mathrm{Fe}(\mathrm{II})$. After preequilibrium of adsorption, the reaction began with the addition of $\mathrm{Fe}(\mathrm{II})$, and the concentrations were detected after $24 \mathrm{~h}$ reaction. Reaction conditions: $10 \mathrm{mg} \mathrm{L}^{-1}$ analytes, $1.0 \mathrm{mM} \mathrm{Fe}(\mathrm{II}), 1 \mathrm{~g} \mathrm{~L}^{-1}$ goethite, $\mathrm{pH} 6.8$ (PIPS buffer), $I=0.1$.

FLU and the insensitivity of FPP exclude the piperazine moiety as a reaction center. Furthermore, the low degradation ratios of $\mathrm{NA}$ and $\mathrm{QN}$ indicate that the carboxyl group and quinolone ring are not reactive. Although $\mathrm{HQN}$ resulted in a high reactivity, the attack of $\bullet \mathrm{OH}$ on $\mathrm{HQN}$ must occur at a phenol group rather than at a quinolone ring, based on the comparison of reaction activity of HQN and QN (Figure 4, S6). This analysis suggests that the ENR reaction center must be on the moiety containing carboxyl and neighboring carbonyl group.

Notably, only part of compounds (FLU, HQN, ENR) in the investigated system have been significantly degraded (Figure 4), which seems to be in conflict with the nonselective property of - $\mathrm{OH}$ radicals. In a classical Fenton reaction, the homogeneous catalysis of $\mathrm{H}_{2} \mathrm{O}_{2}$ by ferrous ions generates $\bullet \mathrm{OH}$, which can attack any organic pollutants in solution without selectivity. In contrast, in our study, $\bullet \mathrm{OH}$ are heterogeneously in situ generated on the surface of $\mathrm{Fe}(\mathrm{II}) / \mathrm{Fe}$ (III) complex, which preferentially attack the adsorbed compounds rather than those free compounds in solution. ${ }^{17}$

Five major ENR degradation products, namely $\mathrm{P} 1-\mathrm{P} 5$, were identified by HPLC-Q-TOF-MS (Figure S7-S8, Table 1), ${ }^{31-34}$ and two transformation pathways were proposed as shown in Figure 5. The first proposed pathway is that the electrophilic attack by $\bullet \mathrm{OH}$ broke the $\mathrm{C}-\mathrm{C}$ bond between the neighboring carboxyl and carbonyl groups (red region of ENR in Figure 
Table 1. Mass Measurements by LC-Q-TOF-MS for ENR and Its Intermediates and Their Proposal Structures

\begin{tabular}{|c|c|c|c|c|c|c|}
\hline Compound & $\mathrm{R}_{\mathrm{t}}$ & $\begin{array}{l}\text { Formula } \\
(\mathrm{M}+\mathrm{H})^{+}\end{array}$ & $\begin{array}{c}\text { Experimental } \\
\operatorname{Mass}(\mathrm{m} / \mathrm{z})\end{array}$ & $\begin{array}{l}\text { Calculated } \\
\operatorname{Mass}(\mathrm{m} / \mathrm{z})\end{array}$ & $\begin{array}{l}\text { ppm } \\
\text { error }\end{array}$ & Proposal structure \\
\hline ENR & 3.75 & $\mathrm{C}_{19} \mathrm{H}_{23} \mathrm{FN}_{3} \mathrm{O}_{3}$ & 360.1722 & 360.1718 & -1.12 & \\
\hline P1 & 1.71 & $\mathrm{C}_{16} \mathrm{H}_{23} \mathrm{FN}_{3} \mathrm{O}_{2}$ & 308.1772 & 308.1769 & 1.04 & \\
\hline $\mathrm{P} 2$ & 2.57 & $\mathrm{C}_{18} \mathrm{H}_{25} \mathrm{FN}_{3} \mathrm{O}_{3}$ & 350.1882 & 350.1874 & 2.16 & \\
\hline P3 & 3.01 & $\mathrm{C}_{18} \mathrm{H}_{25} \mathrm{FN}_{3} \mathrm{O}_{4}$ & 366.1815 & 366.1824 & -2.36 & \\
\hline P4 & 3.34 & $\mathrm{C}_{17} \mathrm{H}_{23} \mathrm{FN}_{3} \mathrm{O}_{3}$ & 336.1708 & 336.1718 & -2.97 & \\
\hline P5 & 3.48 & $\mathrm{C}_{19} \mathrm{H}_{23} \mathrm{FN}_{3} \mathrm{O}_{4}$ & 376.1670 & 376.1667 & 0.77 & \\
\hline
\end{tabular}

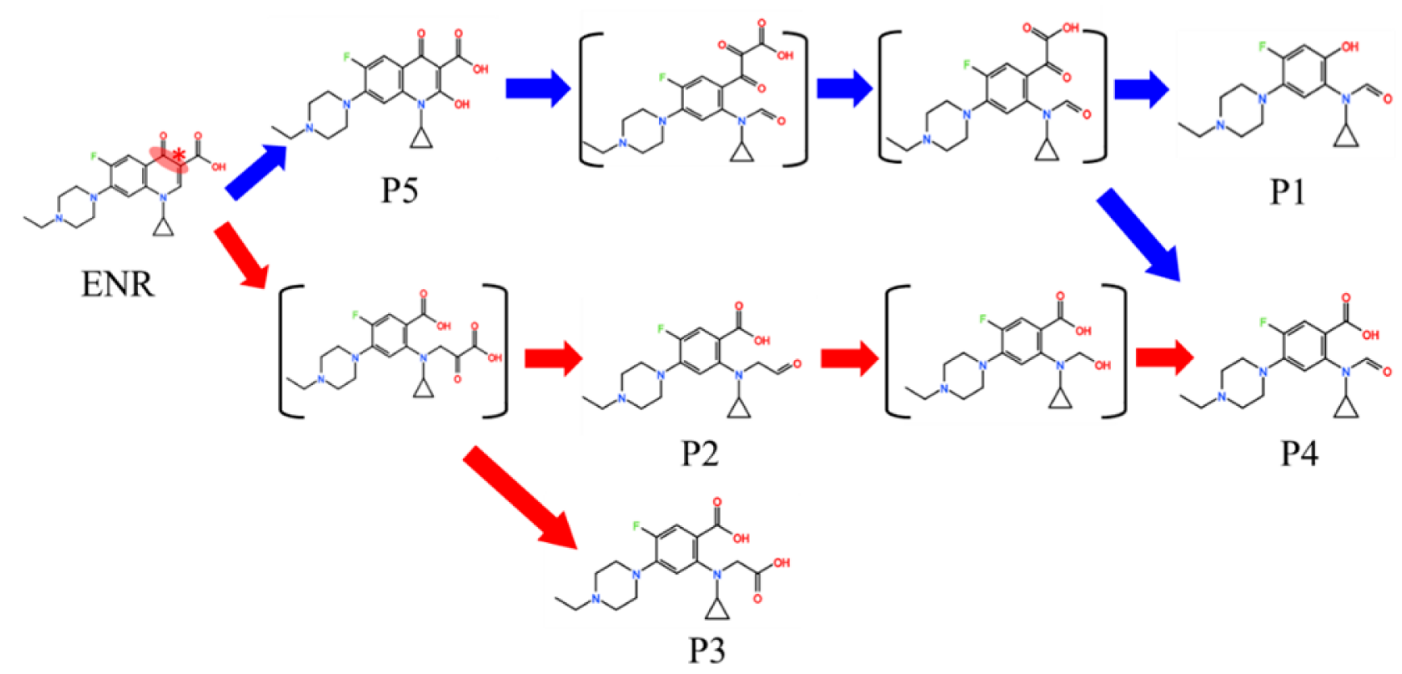

Figure 5. Proposed reaction pathways for ENR transformation.

$5),{ }^{34}$ opening the quinolone ring to generate $\mathrm{P} 2$, the product with a net loss of $\mathrm{CO}$, and $\mathrm{P} 3$, the product with a loss of $\mathrm{C}$ and an addition of $\mathrm{H}_{2} \mathrm{O}$, though the first intermediate product was not detected (red arrows in Figure 5). Further $\bullet \mathrm{OH}$ attack induced the oxidation of $\mathrm{P} 2$ to form P4. Another possible ENR transformation pathway was proposed where the ENR hydroxylation led to the intermediate product P5, followed by a ring-opening reaction and further decarboxylation to generate product P1 (blue arrows in Figure 5).

In addition, the product identification was performed at $\mathrm{pH}$ 4.5 and 9.5. Due to the unfavorable $\mathrm{pH}$ conditions for degradation, only part of ENR products could be detected (Figure S9). Because the ENR products, P2, P4 in the first proposed pathway, and P5 in the second proposed pathway were detected at $\mathrm{pH} 4.5$ and 9.5 (Figure S9), we proposed that the reaction follows the same mechanism in the $\mathrm{pH}$ range 4.59.5. Admittedly, due to the limitation of the Q-TOF-MS detection, we cannot rule out the involvement of other possible degradation pathways.

Our ENR transformation pathways are inconsistent with a previous hypothesis on ciprofloxacin (CIP) degradation, 33,34 which is a fluoroquinolone antibiotic with a structure similar to ENR. The oxidative transformation of CIP on goethite ${ }^{33}$ and hematite ${ }^{34}$ surface was considered to occur via the dealkylation and hydroxylation at the piperazine moiety, with the quinolone ring essentially intact (Figure S10). The contrasting results may 
be ascribed to the difference in electron transfer mechanism. In previous studies, no $\mathrm{Fe}$ (II) was initially present, and CIP is oxidized via direct electron transfer from $\mathrm{N}$ atom of the piperazine ring to iron oxides, generating a surface-bound $\mathrm{Fe}^{\mathrm{II}}$ and CIP radical intermediate. ${ }^{34}$ The CIP radicals then undergo further reactions including $\mathrm{N}$-dealkylation and C-hydroxylation, resulting in the opening of piperazine ring (Figure S10). In contrast, in our system, ENR was oxidized by $\bullet \mathrm{OH}$, which was generated by the electron transfer from $\mathrm{Fe}(\mathrm{II}) / \mathrm{Fe}$ (III) complex to surface molecular oxygen as mentioned above. The reaction occurred at the carboxyl group of ENR due to its headmost approach to the goethite surfaces by the electrostatic interactions between deprotonated carboxyl group and positively charged goethite surfaces $\left(\mathrm{pH}_{\mathrm{pzc}}=8.9\right)$ in the investigated conditions. Due to the strong oxidative capability of $\bullet \mathrm{OH}$, the reaction rate (within several minutes) is significantly faster than that in previous reports (over $65 \mathrm{~h}$ ). ${ }^{34}$

However, NA with a carboxyl group $\left(\mathrm{p} K_{\mathrm{a}}=2.14\right)$ was inert (Figure 4), indicating that the presence of a carboxyl group itself is not sufficient to explain the reactivity. In fact, the quinolone ring was readily opened by the electrophilic attack of $\bullet \mathrm{OH}$ at the $\mathrm{C} 3$ position (marked by an asterisk in Figure 5), which is of the highest electron density in the ring in the presence of both carboxyl and the adjacent carbonyl groups. ${ }^{35}$ Thus, both the surface adsorption and the electron density distribution in the molecule determine the reactive site and transformation pathway.

Environmental Significance. Due to its relative large specific surface area (ca. $50-200 \mathrm{~m}^{2} \mathrm{~g}^{-1}$ ) and reactive surface functional groups (e.g., hydroxyl groups), goethite is traditionally considered as a good adsorbent for organic pollutants. As demonstrated by the results of this work, however, goethite not only act as an adsorbent but also as a reagent involved in the degradation of fluoroquinolones.

Goethite with adsorbed $\mathrm{Fe}$ (II) could fast degrade ENR at the anaerobic/aerobic interface. ESR study demonstrated that $\bullet \mathrm{OH}$ were generated and involved in the ENR degradation. Adsorbed $\mathrm{Fe}(\mathrm{II})$ was thought to play a key role in the formation of $\bullet \mathrm{OH}$. Generally, dissolved $\mathrm{Fe}^{2+}$ is considered to be inefficient for pollutant degradation in natural aerobic condition due to rapid oxidation of $\mathrm{Fe}^{2+}$ by dissolve $\mathrm{O}_{2}$. However, goethite can be bioreduced by DIRB in anaerobic condition and in situ generated adsorbed $\mathrm{Fe}(\mathrm{II})$. Then $\mathrm{Fe}$ (II) associated with goethite can degrade the adsorbed ENR with high reactivity by the generation of $\bullet \mathrm{OH}$ when the complex comes to aerobic/anaerobic interface. This hypothesis was proven by our results of the anaerobic production of $\mathrm{Fe}$ (II) by incubation of MR-1 in goethite suspension and fast aerobic ENR degradation by bioreduced goethite.

Since $\bullet \mathrm{OH}$ is in situ formed on the mineral surfaces, the ENR adsorption on $\mathrm{Fe}$ oxide surfaces play a critical role in determining the reaction rate and extent. Considering that $\bullet \mathrm{OH}$ is a short-lived, highly reactive oxidizing agent, it can be reasonably extrapolated that the $\bullet \mathrm{OH}$ formation pathway proposed here should have a great impact on the environmental fate of antibiotics and other organic pollutants. Thus, this work highlights a potential transformation pathway of contaminants in the natural environment that may have been underappreciated previously.

\section{ASSOCIATED CONTENT}

\section{Supporting Information}

The Supporting Information is available free of charge on the ACS Publications website at DOI: 10.1021/acs.est.6b03054.

Details of Microbial Incubation; Aerobic degradation of ENR with bioreduced goethite; ENR transformation products identification analysis; $\mathrm{Fe}$ (II) determination; analytical procedure; and additional figures (PDF)

\section{AUTHOR INFORMATION}

\section{Corresponding Author}

*Phone: +86 106284 9523; fax: +86 106284 9523; e-mail: cyjing@rcees.ac.cn.

\section{Notes}

The authors declare no competing financial interest.

\section{ACKNOWLEDGMENTS}

We acknowledge the financial support of the National Key Basic Research Program of China (2014CB441102), the Strategic Priority Research Program of the Chinese Academy of Sciences (XDB14020301), and the National Natural Science Foundation of China (21477144, 41425016, and 21007080), and Young Scientists Fund of RCEES (RCEES-QN20130017F).

\section{REFERENCES}

(1) Larson, C. China's lakes of pig manure spawn antibiotic resistance. Science 2015, 347, 704.

(2) Reardon, S. Antibiotic resistance sweeping developing world. Nature 2014, 509, 141-142.

(3) Qin, X.; Liu, F.; Wang, G.; Li, L.; Wang, Y.; Weng, L. Modeling of levofloxacin adsorption to goethite and the competition with phosphate. Chemosphere 2014, 111, 283-290.

(4) Trivedi, P.; Vasudevan, D. Spectroscopic investigation of ciprofloxacin speciation at the goethite-water interface. Environ. Sci. Technol. 2007, 41, 3153-3158.

(5) Novo, A.; André, S.; Viana, P.; Nunes, O. C.; Manaia, C. M. Antibiotic resistance, antimicrobial residues and bacterial community composition in urban wastewater. Water Res. 2013, 47, 1875-1887.

(6) Borch, T.; Kretzschmar, R.; Kappler, A.; Van Cappellen, P.; Ginder-Vogel, M.; Voegelin, A.; Campbell, K. Biogeochemical redox processes and their impact on contaminant dynamics. Environ. Sci. Technol. 2010, 44, 15-23.

(7) Luan, F.; Liu, Y.; Griffin, A. M.; Gorski, C. A.; Burgos, W. D. Iron(III)-bearing clay minerals enhance bioreduction of nitrobenzene by Shewanella putrefaciens CN32. Environ. Sci. Technol. 2015, 49, $1418-1426$

(8) Luan, F.; Gorski, C. A.; Burgos, W. D. Linear free energy relationships for the biotic and abiotic reduction of nitroaromatic compounds. Environ. Sci. Technol. 2015, 49, 3557-3565.

(9) Gorski, C. A.; Screr, M. M. Influence of magnetite stoichiometry on $\mathrm{Fe}^{\mathrm{II}}$ uptake and nitrobenzene reduction. Environ. Sci. Technol. 2009, 43, 3675-3680.

(10) Cao, F.; Liu, T. X.; Wu, C. Y.; Li, F. B.; Li, X. M.; Yu, H. Y.; Tong, H.; Chen, M. J. Enhanced biotransformation of DDTs by an iron- and humic-reducing bacteria Aeromonas hydrophila HSO1 upon addition of goethite and anthraquinone-2,6-disulphonic disodium salt (AQDS). J. Agric. Food Chem. 2012, 60, 11238-11244.

(11) Mohatt, J. L.; Hu, L.; Finneran, K. T.; Strathmann, T. J. Microbially mediated abiotic transformation of the antimicrobial agent sulfamethoxazole under iron-reducing soil conditions. Environ. Sci. Technol. 2011, 45, 4793-4801.

(12) Amstaetter, K.; Borch, T.; Larese-Casanova, P.; Kappler, A. Redox transformation of arsenic by $\mathrm{Fe}(\mathrm{II})$-activated goethite $(\alpha$ FeOOH). Environ. Sci. Technol. 2009, 44, 102-108. 
(13) Jiang, S.; Lee, J.-H.; Kim, D.; Kanaly, R. A.; Kim, M.-G.; Hur, H.G. Differential arsenic mobilization from As-bearing ferrihydrite by iron-respiring Shewanella strains with different arsenic-reducing activities. Environ. Sci. Technol. 2013, 47, 8616-8623.

(14) Lin, J.; Xu, Y.; Brookes, P. C.; He, Y.; Xu, J. Spatial and temporal variations in pentachlorophenol dissipation at the aerobic-anaerobic interfaces of flooded paddy soils. Environ. Pollut. 2013, 178, 433-440.

(15) Hayat, T.; Ding, N.; Ma, B.; He, Y.; Shi, J.; Xu, J. Dissipation of pentachlorophenol in the aerobic-anaerobic interfaces established by the rhizosphere of rice (Oryza sativa L.) root. J. Environ. Qual. 2011, 40, 1722-1729.

(16) Roden, E. E.; Sobolev, D.; Glazer, B.; Luther, G. W. Potential for microscale bacterial Fe redox cycling at the aerobic-anaerobic interface. Geomicrobiol. J. 2004, 21, 379-391.

(17) Ai, Z. H.; Gao, Z. T.; Zhang, L. Z.; He, W. W.; Yin, J. J. Coreshell structure dependent reactivity of $\mathrm{Fe} @ \mathrm{Fe}_{2} \mathrm{O}_{3}$ nanowires on aerobic degradation of 4-chlorophenol. Environ. Sci. Technol. 2013, 47, 5344-5352.

(18) Wang, L.; Cao, M.; Ai, Z. H.; Zhang, L. Z. Dramatically enhanced aerobic atrazine degradation with $\mathrm{Fe} @ \mathrm{Fe}_{2} \mathrm{O}_{3}$ core-shell nanowires by tetrapolyphosphate. Environ. Sci. Technol. 2014, 48, 3354-3362.

(19) Yan, W.; Wang, H.; Jing, C. Adhesion of Shewanella oneidensis MR-1 to goethite: a two-dimensional correlation spectroscopic study. Environ. Sci. Technol. 2016, 50, 4343-4349.

(20) Huang, C. H.; Ren, F. R.; Shan, G. Q.; Qin, H.; Mao, L.; Zhu, B. Z. Molecular mechanism of metal-independent decomposition of organic hydroperoxides by halogenated quinoid carcinogens and the potential biological implications. Chem. Res. Toxicol. 2015, 28, 831837.

(21) Latta, D. E.; Gorski, C. A.; Scherer, M. M. Influence of Fe ${ }^{2+}$ catalysed iron oxide recrystallization on metal cycling. Biochem. Soc. Trans. 2012, 40, 1191-1197.

(22) Zarzycki, P.; Kerisit, S.; Rosso, K. M. Molecular dynamics study of $\mathrm{Fe}(\mathrm{II})$ adsorption, electron exchange, and mobility at goethite $(\alpha-$ FeOOH) surfaces. J. Phys. Chem. C 2015, 119, 3111-3123.

(23) Zhu, B. Z.; Kalyanaraman, B.; Jiang, G. B. Molecular mechanism for metal-independent production of hydroxyl radicals by hydrogen peroxide and halogenated quinones. Proc. Natl. Acad. Sci. U. S. A. 2007, 104, 17575-17578.

(24) Zhu, B. Z.; Zhao, H. T.; Kalyanaraman, B.; Liu, J.; Shan, G. Q.; $\mathrm{Du}$, Y. G.; Frei, B. Mechanism of metal-independent decomposition of organic hydroperoxides and formation of alkoxyl radicals by halogenated quinones. Proc. Natl. Acad. Sci. U. S. A. 2007, 104, 3698-3702.

(25) Fu, H.; Zhang, L.; Zhang, S.; Zhu, Y.; Zhao, J. Electron spin resonance spin-trapping detection of radical intermediates in $\mathrm{N}$-doped $\mathrm{TiO}_{2}$-assisted photodegradation of 4-chlorophenol. J. Phys. Chem. B 2006, 110, 3061-3065.

(26) Jones, A. M.; Griffin, P. J.; Collins, R. N.; Waite, T. D. Ferrous iron oxidation under acidic conditions-the effect of ferric oxide surfaces. Geochim. Cosmochim. Acta 2014, 145, 1-12.

(27) Bataineh, H.; Pestovsky, O.; Bakac, A. pH-induced mechanistic changeover from hydroxyl radicals to iron(IV) in the Fenton reaction. Chem. Sci. 2012, 3, 1594-1599.

(28) Yang, X. J.; Xu, X. M.; Xu, J.; Han, Y. F. Iron oxychloride ( $\mathrm{FeOCl})$ : an efficient fenton-like catalyst for producing hydroxyl radicals in degradation of organic contaminants. J. Am. Chem. Soc. 2013, 135, 16058-16061.

(29) Boland, D. D.; Collins, R. N.; Miller, C. J.; Glover, C. J.; Waite, T. D. Effect of solution and solid-phase conditions on the $\mathrm{Fe}(\mathrm{II})-$ accelerated transformation of ferrihydrite to lepidocrocite and goethite. Environ. Sci. Technol. 2014, 48, 5477-5485.

(30) Kappler, A.; Straub, K. L. Geomicrobiological cycling of iron. Rev. Mineral. Geochem. 2005, 59, 85-108.

(31) Ardo, S. G.; Nelieu, S.; Ona-Nguema, G.; Delarue, G.; Brest, J.; Pironin, E.; Morin, G. Oxidative degradation of nalidixic acid by nanomagnetite via $\mathrm{Fe}^{2+} / \mathrm{O}_{2}$-mediated reactions. Environ. Sci. Technol. 2015, 49, 4506-4514.
(32) Maia, A. S.; Ribeiro, A. R.; Amorim, C. L.; Barreiro, J. C.; Cass, Q. B.; Castro, P. M. L.; Tiritan, M. E. Degradation of fluoroquinolone antibiotics and identification of metabolites/transformation products by liquid chromatography-tandem mass spectrometry. J. Chromatogr. A 2014, 1333, 87-98.

(33) Zhang, H.; Huang, C.-H. Adsorption and oxidation of fluoroquinolone antibacterial agents and structurally related amines with goethite. Chemosphere 2007, 66, 1502-1512.

(34) Martin, S.; Shchukarev, A.; Hanna, K.; Boily, J. F. Kinetics and mechanisms of ciprofloxacin oxidation on hematite surfaces. Environ. Sci. Technol. 2015, 49, 12197-12205.

(35) Fan, X.; Hao, H.; Wang, Y.; Chen, F.; Zhang, J. Fenton-like degradation of nalidixic acid with $\mathrm{Fe}^{3+} / \mathrm{H}_{2} \mathrm{O}_{2}$. Environ. Sci. Pollut. Res. 2013, 20, 3649-3656. 